\title{
(Re)introducing medicinal cannabis
}

Laurence E Mather PhD, FANZCA, FRCA Emeritus Professor of Anaesthesial

Evert R Rauwendaal Social Worker

Vivienne L Moxham-Hal BA, BSC,

MHealthPol, Secretary

Alex D Wodak AM,FRACP, FAChAM, FAFPHM, Emeritus Consultant

1 Sydney Medical School, University of Sydney, Sydney, NSW.

2 Alcohol and Drug Services, St Vincent's Hospital, Sydney, NSW.

3 Australian Drug Law Reform Foundation Sydney, NSW.

Imather@ med.usyd.edu.au

doi: 10.5694/mial3.10728
T he medicinal use of cannabis (Box) was prohibited in Australia some 50 years ago, at a time when scientific knowledge about it was meagre. It is now clear that cannabis has genuine medicinal utility, but this has been largely overlooked, with research and society's attention, in most parts of the world, being directed towards the hazards of its recreational use rather than the benefits of its medicinal use. ${ }^{1,2}$ We maintain that consideration of policy for medicinal cannabis should be kept separate from consideration of recreational cannabis.

In May 2013, a New South Wales parliamentary committee comprising members of five political parties unanimously recommended making medicinal cannabis available for selected conditions. Its report (the NSW Report) stated:

in general terms medical cannabis has potential as an effective treatment for some medical conditions with appropriate safeguards in place [and] cannabis products are emerging as a promising area of medicine ... ${ }^{3}$

We agree, and add that national acceptance of medicinal cannabis should be implemented based exclusively on evidence of its clinical efficacy, safety and cost-effectiveness, and that necessary legal reforms permitting medical prescription should be enacted, as has been done in many countries.

\section{Evidence}

With any drug, the evidence must show that, when used for a specific approved purpose, its benefits outweigh its risks - rather than its superiority over other treatments.

A number of prominent inquiries have reviewed evidence for medicinal cannabis, and all have supported its use. ${ }^{4-6}$ Moreover, the American Medical Association reviewed the evidence in 2009 and recommended rescheduling cannabinoid-based medicines to allow their legal prescription in the United States.?

The NSW Report stated that:

on the present medical evidence, cannabis based treatments will only be appropriate for a small number of people in specific circumstances, and under the supervision of medical practitioners with suitable expertise. Those patients would necessarily be people with severe and distressing symptoms that are not able to be addressed by existing medications. ${ }^{3}$

Such evidence has been subjected to many published reviews and commentaries, which support the use of cannabis for symptomatic relief, rather than curative treatment, of many, mainly neuropathic, conditions. A British pharmacological review noted the "wide range of pharmacological strategies expected to maximize the beneficial therapeutic

\author{
Summary \\ - After considering extensive scientific and medical \\ evidence, a New South Wales Legislative Council \\ multiparty committee recommended that medicinal \\ cannabis should lawfully be made available for selected- \\ use pharmacotherapy. \\ - The evidence indicates that cannabis has genuine \\ medicinal utility in patients with certain neuropathic \\ conditions, with acceptable levels of risk from mostly \\ mild side effects. \\ - The potential medical benefits of cannabis \\ pharmacotherapy have largely been overlooked, with \\ research and society's attention, in most parts of the \\ world, being directed towards the hazards of its \\ recreational use. \\ - The NSW Government has since dismissed the \\ unanimous and compassionate recommendations of \\ their committee.
}

activate cannabinoid receptors directly" ${ }^{\prime 8}$ A US medicolegal review concluded that:

advocacy is a poor substitute for dispassionate analysis, and ... popular votes should not be allowed to trump scientific evidence in deciding whether or not marijuana is an appropriate pharmaceutical agent to use in modern medical practice.

A German medical review found a preponderance of favourable controlled trials for treatment of a range of conditions including spasticity resulting from disseminated sclerosis (nine favourable, three unfavourable), chemotherapyinduced nausea and vomiting (40 favourable, one unfavourable), HIV/AIDS-related cachexia (seven favourable, none unfavourable), cancer-related cachexia (three favourable, one unfavourable), chronic neuropathic pain (12 favourable, two unfavourable) and other chronic (cancer, rheumatism, fibromyalgia) pain (11 favourable, two unfavourable). ${ }^{10}$

\section{Safety}

Whereas most recent studies of medicinal cannabis involve medicinal-grade cannabis in institutionally approved trials, studies of recreational cannabis are largely based on streetgrade cannabis in unknown circumstances, and are therefore of questionable value for either explicit pharmacology or extrapolation to patients undergoing cannabis pharmacotherapy.

The unauthorised use of cannabis as a medicine in Australia is widespread, ${ }^{11}$ suggesting significant demand, but this use is neither supervised nor regulated. Like any medication, cannabis will be safest if the smallest dose is prescribed for the shortest period required to gain the desired therapeutic effect, under medical supervision. 


\section{Cannabis terminology, substances and preparations}

Cannabis (Latin, meaning hemp)

- Portions of the Cannabis sativa plant producing a resinous exudate secretion rich in specified terpenoid chemicals.

Historical source of fibre, food, dietary supplement and medicine (as a tincture).

- Also known as marijuana or marihuana, and by a variety of street names, and varietal names related to botanical cultivars.

- Concentrations of chemical constituents can vary by plant strain and conditions of growing, storage, harvest and preparation. Standardisation of any plant material, extract or blend for medicinal use is essential, and the chemovar is the most reliable predictor of medicinal value.

\section{Cannabinoids}

- Substances (regardless of chemical structure and whether they are natural or synthetic) that bind to biological receptors and produce the classical spectrum of pharmacological effects demonstrated by extracts of $C$. sativa.

- Principal botanical cannabinoids are tetrahydrocannabinol (THC) and cannabidiol (CBD), a major non-psychoactive component that attenuates the cognitive effects of THC and may have useful effects of its own.

- With all modes of administration, chemical components of cannabis other than cannabinoids probably contribute to the medicinal and other effects; pharmacological effects may therefore be enhanced by synergies between constituents of cannabis not present in isolated or synthetic cannabinoid pharmaceuticals.

\section{Preparations currently available}

Synthetic THC (dronabinol [Marinol, Solvay Pharmaceuticals]): oral capsule.

Synthetic analogue of THC (nabilone [Cesamet, Meda Pharmaceuticals]): oral capsule.

- Natural THC (Namisol, Echo Pharmaceuticals): early development; oral tablet with novel emulsifying drug delivery technology.

Whole-plant extract; THC:CBD, 2:1 (Cannador, IKF Berlin): oral capsule.

- Standardised plant matter in granular form; THC:CBD, 19:1 (Bedrocan), 12:< 1 (Bedrobinol), 6:75 (Bediol), 14:<1 (Bedica): produced by Bedrocan BV for the Netherlands Ministry of Health, Welfare and Sport; pharmacy-supplied for vaporisation or tea preparation.

Botanical cannabis extract with minor cannabinoid and other plant-derived substances; $2.7 \mathrm{mg}$ THC and $2.5 \mathrm{mg}$ CBD per $0.1 \mathrm{~mL}$ (nabiximols [Sativex, Bayer]): oromucosal spray (combination of sublingual, buccal and ingested routes).

Reviews of medicinal cannabis used under essentially controlled conditions indicate that the frequencies of both side effects and dependence are low. One specific review on side effects reported that they were modest, with only $10 \%$ of patients choosing to discontinue their treatment. A greater incidence was found for cannabis over placebo treatment for disorientation ( $4 \% \mathrm{v} 0.5 \%)$, disturbance in attention $(3.7 \% \mathrm{v}$ $0.1 \%)$, feeling drunk ( $2.9 \% \mathrm{v} 0.4 \%)$, euphoric mood $(2.2 \% \mathrm{v}$ $0.9 \%)$, depression $(1.9 \% \mathrm{v} 0.8 \%)$, memory impairment $(1.4 \%$ v $0.1 \%)$ and dissociation ( $1.7 \%$ v $0.1 \%)$. Tolerance did not develop, and the review concluded that abuse or dependence "is likely to occur in only a very small proportion of recipients" ${ }^{12}$ Longer-term studies have not indicated new safety concerns after several years of administration. ${ }^{13}$

Doctors and pharmacists will require further education about medicinal cannabis and how to instruct patients in its use. Criteria for patient selection will need development. As for opioid analgesics, risks of diversion of medicinal cannabis must be minimised. Nonetheless, it is hard to envisage how significant diversion will be necessary when, nationally, 92\% of respondents to the 2012 Illicit Drug Reporting System survey reported that hydroponic cannabis was "easy" or "very easy" to obtain. ${ }^{14}$ Moreover, in the US states that have passed "medical marijuana" laws, no increase was found in the prevalence of use overall or among adolescents. ${ }^{15}$ We thus recommend against dismissing medicinal cannabis on the spurious grounds that it "sends the wrong message".

As with opioid analgesics, there is no standard pharmacotherapeutic dose for cannabis. Patients must decide for themselves what dose gives the best balance between wanted and unwanted effects. Dose titration by patients requires a reliable medication and mode of administration. As patients differ in their symptoms and response, effects and side effects would need repeated evaluations against checklists, and any large changes in titrated dosage would need consideration.

\section{Legal aspects}

Although the NSW Report recommended legal changes that essentially decriminalise possession and use by approved people, it made no recommendations about how cannabis should be supplied lawfully. Evidence was presented to the inquiry that facilitatory changes were possible should there be a will. Legal experts need to determine the legal aspects of medicinal cannabis.

\section{Supply}

The NSW Report considered various options for supply, from botanical raw material (eg, permission for patients to grow their own plants) to prescribed finished pharmaceutical products, presently restricted to nabiximols. Quality control is imperative. Patient satisfaction from legal selfsourced supplies of home-grown cannabis in Canada was reported as "poor". 16

The production and supply of medicinal cannabis should not differ from other botanical medicines. The Netherlands Ministry of Health, Welfare and Sport procures medicinal grade cannabis from an authorised agricultural company that cultivates the plant in compliance with current European standards and is subject to strict quality control. It is dispensed by a qualified pharmacist in its raw botanical form (milled vegetable matter) by prescription. Patient information includes instructions for use with a vaporiser or preparation as a tea. ${ }^{17} \mathrm{~A}$ short video illustrates the entire process. ${ }^{18}$ We recommend that pharmacists be authorised to dispense medicinal-grade cannabis in its raw form, with extracts of the same material (eg, nabiximols oromucosal spray) offered as an alternative finished product. Medicinal cannabis for local use could be purchased through official channels, perhaps initially from overseas, to assure quality.

As noted in the NSW Report, affordability, especially to disadvantaged patients, is a crucial consideration. Raw botanical material may be more affordable than nabiximols, presumably at the expense of convenience. If these options are both unaffordable, patients will cultivate their own supplies, purchase from the black market, or continue to suffer. In particular, older, debilitated or terminally ill patients should not be put in this position.

\section{Administration}

Most commonly, botanical cannabis is administered by transpulmonary, peroral, or oral transmucosal modes (Box).

The various pharmacologically active substances can be vaporised for inhalation by smoking or by an electrically heated vaporiser. The vaporised substances become rapidly absorbed in the lungs, with the rapidity of absorption 
increasing the effects. Smoked cannabis has been found to be effective in reducing pain intensity and improving sleep, and is well tolerated without excessive adverse effects in treatment-resistant patients. ${ }^{19}$ However, smoking is not an accurate dosage method and is not acceptable to many patients, nor is it medically acceptable except, perhaps, in patients with a short life expectancy or as an expedient self-medication treatment. Vaporisation in an electrically heated vaporiser produces comparable results ${ }^{20}$ and is preferable.

Although peroral administration of cannabis is the simplest mode, its unfavourable pharmacokinetics in existing proprietary products and in home-prepared forms (eg, as a tea or an olive oil extract) make it harder for patients to selftitrate their dosage. Oral inhalation via a vaporiser has advantages compared with oral ingestion, including superior titration and the avoidance of swallowing in patients with nausea. Nabiximols oromucosal spray offers greater consistency and convenience of use than other modes, with an absorption rate comparable to that for oral capsules. ${ }^{21}$

The effects of cannabis are primarily related to its dose and chemical composition, but can be attenuated by administration modes that avoid rapid absorption of a large dose. While the mood-altering effects of cannabis are generally eschewed with medicinal use, patients may find the experience pleasurable, relaxing and sleep-promoting. In the end, patients have to find their own best compromise between cost, convenience and ability to match doses to their needs.

\section{Conclusion}

The benefits of cannabinoid pharmacotherapy can be substantial. The risks are generally modest and must be weighed against those of not treating the symptoms or of alternative treatments. $^{22}$

In Australia, medicinal cannabis currently has strong community support (69\%), with research into its use being even more strongly supported $(74 \%){ }^{23}$ The number of Medline-indexed publications has doubled each decade, from about 400 in 1990 to about 1600 in 2010. A stronger medical consensus is emerging. In a hypothetical case of a 68 -year-old woman in pain with advanced cancer, $76 \%$ of respondents indicated that they would recommend medicinal cannabis to alleviate her symptoms. ${ }^{24}$ We do not envisage terminal illness to be a sole entry criterion to cannabis pharmacotherapy.

With medicinal cannabis now available legally in 20 US states, there is an undeniable shift towards recognising its pharmacotherapeutic potential. It is time to implement the use of medicinal cannabis in Australia. The NSW Report has produced an excellent starting point. Changing the laws to allow such pharmacotherapy presents more of a challenge but is not an insurmountable obstacle.

A civilised and compassionate country that supports evidence-based medicine and policy should acknowledge that medicinal cannabis is acceptably effective and safe, and probably also cost-effective, especially when the costs of resource use and improvement to the lives and functionality of patients and carers are considered.

There is certainly more to learn about medicinal cannabis, but we know more than enough to act now. As
Bradford Hill has observed: "All scientific knowledge is incomplete ... That does not confer upon us a freedom to ignore the knowledge we already have, or to postpone the action that it appears to demand" ${ }^{25}$

Note: The NSW Government tabled its response to the NSW Report recommendations in Parliament on 15 November 2013 accepting only recommendation 1 that "the [NSW] Minister for Health write to the Commonwealth Minister for Health and Ageing expressing in principal [sic] support for the timely, evidence based expansion of access to approved cannabis pharmacotherapies by additional patient groups, including those suffering from chronic pain for whom existing pain management is not effective; [and that] further clinical trials of pharmaceutical cannabis products to continue to build this evidence base; and [for] approved pharmaceutical cannabis products to be affordable to patients". The remaining recommendations $2-5$, which would essentially permit the lawful use of medicinal-grade botanical cannabis, were rejected. A copy of the Government response, along with a critique, has been prepared by the Australian Drug Law Reform Foundation (http://adlrf.org.au/medical-cannabis [accessed Nov 2013]).

Competing interests: Laurence Mather was a member of the Working Party on the Use of Cannabis for Medical Purposes convened by the Office of the Premier of NSW that produced its report in 2000-2001. He wrote a submission for the NSW Parliament General Purpose Standing Committee No. 4 (GPSC) inquiry into the use of cannabis for medical purposes. He has been an Emeritus Professor of the University of Sydney since 2007; previously, he received supported research grants and paid speaker's fees in association with his discipline of anaesthesia and pain medicine, all unrelated to this article. Evert Rauwendaal, Vivienne Moxham-Hall and Alex Wodak are members of the Australian Drug Law Reform Foundation and co-wrote a submission for, and gave oral evidence to, the GPSC inquiry.

Provenance: Not commissioned; externally peer reviewed.

1 Nutt DJ, King LA, Nichols DE. Effects of Schedule I drug laws on neuroscience research and treatment innovation. Nat Rev Neurosci 2013; 14: 577-585.

2 Gross M. Drugs prohibition is criminals' gain, neuroscience's loss. Curr Biol 2013; 23: R585-R588.

3 General Purpose Standing Committee No. 4. The use of cannabis for medical purposes (Report 27). Sydney: NSW Parliament, May 2013. http://www.parliament.nsw.gov.au/prod/parlment/committee.nsf/0/fdb7842 246a5ab7lca257b6c0002f09b/\$FILE/Final\%20Report\%20-\%20The\%20use\%20of\%20cannnabis\%20 for\%20medical\%20purposes.pdf (accessed Aug 2013).

4 Joy JE, Watson SJ Jr, Benson JA Jr, editors. Marijuana and medicine: assessing the science base. Washington, DC: National Academy of Sciences, 1999. http://www.nap.edu/readingroom/books/marimed (accessed Aug 2013).

5 Select Committee on Science and Technology, UK. Second Report, 2001: therapeutic uses of cannabis. http:// www.parliament.the-stationery-office.co.uk/pa/ld200001/ldselect/ldsctech/50/5002.htm (accessed Aug 2013).

6 NSW Government. Report of the Working Party on the Use of Cannabis for Medical Purposes. Sydney: Office of the Premier of NSW, Volumes 1 to 3, 2000; Volume 4, 2001.

7 Report 3 of the Council on Science and Public Health (I-09). Use of cannabis for medicinal Purposes (Resolutions 910, I-08; 921, I-08; and 229, A-09) (Reference Committee K). American Medical Association, 2009. http://www.ama-assn.org//resources/doc/csaph/i09csaph3ft.pdf (accessed Aug 2013).

8 Pertwee RG. Targeting the endocannabinoid system with cannabinoid receptor agonists: pharmacological strategies and therapeutic possibilities. Philos Trans R Soc Lond B Biol Sci 2012; 367: 3353-3363.

9 Cohen PJ. Medical marijuana: the conflict between scientific evidence and political ideology. JPain Palliat Care Pharmacother 2009; 23(1): 4-25, 23(2): 120-140.

10 Grotenhermen F, Müller-Vahl K. The therapeutic potential of cannabis and cannabinoids. Dtsch Arztebl Int 2012; 109: 495-501.

11 Swift W, Gates P, Dillon P. Survey of Australians using cannabis for medical purposes. Harm Reduct J 2005; 2: 18.

12 Robson P. Abuse potential and psychoactive effects of -9-tetrahydrocannabinol and cannabidiol oromucosal spray (Sativex), a new cannabinoid medicine. Expert Opin Drug Saf 2011; 10: 675-685.

13 Serpell MG, Notcutt W, Collin C. Sativex long-term use: an open-label trial in patients with spasticity due to multiple sclerosis. J Neurol 2013; 260: 285-295.

14 Stafford J, Burns L. Australian drug trends 2012. Findings from the Illicit Drug Reporting System (IDRS). (Australian Drug Trends Series No. 91.) Sydney: National Drug and Alcohol Research Centre, University of New South Wales, 2013. http://ndarc.med.unsw.edu.au/sites/default/files/ndarc/resources/ National\%20IDRS\%20report\%202012.pdf (accessed Nov 2013).

15 Lynne-Landsman SD, Livingston MD, Wagenaar AC. Effects of state medical marijuana laws on adolescent marijuana use. Am J Public Health 2013; 103: 1500-1506.

16 Lucas P. It can't hurt to ask; a patient-centered quality of service assessment of Health Canada's medical cannabis policy and program. Harm Reduct J 2012; 9: 2

17 Hazekamp A, Heerdink ER. The prevalence and incidence of medicinal cannabis on prescription in The Netherlands. Eur J Clin Pharmacol 2013; 69: 1575-1580.

18 CIBG Ministerie van Volksgezondheid, Welzijn en Sport Informatieclip: The Office of Medicinal Cannabis. BMC English. http://youtu.be/hE60il2pl_k (accessed Aug 2013).

19 Corey-Bloom J, Wolfson T, Gamst A, et al. Smoked cannabis for spasticity in multiple sclerosis: a randomized, placebo-controlled trial. CMAJ 2012; 184: 1143-1150.

20 Wilsey B, Marcotte T, Deutsch R, et al. Low-dose vaporized cannabis significantly improves neuropathic pain. JPain 2013; 14: 136-148.

21 Karschner EL, Darwin WD, Goodwin RS, et al. Plasma cannabinoid pharmacokinetics following controlled oral delta9-tetrahydrocannabinol and oromucosal cannabis extract administration. Clin Chem 2011; 57: 66-75.

22 Carter GT, Flanagan AM, Earleywine M, et al. Cannabis in palliative medicine: improving care and reducing opioid-related morbidity. Am J Hosp Palliat Care 2011; 28: 297-303.

23 Australian Institute of Health and Welfare. 2010 National Drug Strategy Household Survey report. Canberra: AlHW, 2011. (AlHW Cat. No. PHE 145; Drug Statistics Series No. 25.) http://www.aihw.gov.au/publicationdetail/?id=32212254712 (accessed Aug 2013).

24 Adler JN, Colbert JA. Clinical decisions: medicinal use of marijuana - polling results. NEngl J Med 2013; 368 : e30.

25 Hill AB. The environment and disease: association of causation? Proc R Soc Med 1965; 58: 292-300. 
For debate

MJA Eric Dark Comp

762 MJA $199(11) \cdot 16$ December 2013 